CYANOSIS AND INDISCRIMINATE SELFDRUGGING.

To the Editors of THE LANCET.

SIRS, - I have read with pleasure and also with no little beaffit the interesting lecture by Dr. Thomas Oliver which appeared in THE LANCET, Dec. 29th, 1906, p. 1772, which warningly illustrates the ill-effects upon the body which may be brought about by the indiscriminate self-drugging with medicaments ordinarily regarded by the public as noninjurious even if non effectual. It is scarcely to be expected that the lay person should know whether or not certain drugs are or are not more than ordinarily injurious; as a matter of fact, he or she commonly regards them as being safe principally on account of the ease with which they can be procured and the publicity given to the class of medicine by its exposure in the windows and show cases of chemists' shops, contained, $\mathrm{zs}$ it usually is, in the pleasing and portable litile tin-stoppered bottle.

The lecture recalls to my mind two cases which have occurred in my own practice during the last 12 months, in both instances in women, and I should perhaps not have noted the effect of this class of drug had it not been that the symptoms of the second case were practically identical with those of the first. The first case was that of a nurse, aged 30 years, who for some time had suffered from dysmenorrbcea, but which latterly had been of such severity as to cause her to resort to drugging; on the night the incident occurred she had taken two antikamnia pellets but as she got no relief from them within an hour she took two more. In about an hour's time she was seized with violent pains in the lower part of the abdomen, accompanied by an urgent condition of dyspnœu with pallid face, blue lips, ears, nose, and finger tips; the pulse- and respiration-rates were both increased in frequency. She said she had at the time a feeling of impending death. She was given a little brandy-and-water and when I saw her I ordered fomentations to the lower abdomen. She was apparently quite well again in an hour and a half.

The second case, also a nurse, aged 27 years, although robust looking, had suffered six years previously from scarlet fever complicated by pleurisy and albuminuria ; she was never free from a slight albuminuria and had recently been troubled with nasty headaches on and off. She was given four antipyrine pellets by another nurse who was in the habit of taking them for headache. She took all four at once and about half an hour later she was taken ill and with the exception of the absence of abdominal pain she had similar symptoms to the previous case, but had a more marked and prolonged initial faint. She was put to bed and was given a little brandy-and-water with hot applications over the præcordial region, and was apparently quite well again in about three hours.

I am, Sirs, yours faithfully, Joseph BEARD, F.R.C.S. Edin., D.P.H. Camb. Bootle, Jan. 8th, 1907.

\section{THE CASE OF GEORGE EDALJI: A QUESTION FOR OPHTHALMO- LOGISTS.}

To the Editors of THE LANCET.

SIRs,-Might $\mathrm{I}$ ask you in the cause of justice to permit me to put the following question to those of your readers who are engaged in eye practice :-

"Do you consider it physically possible for Mr. George Edalji, whose degree of myopic astigmatism as determined by retinoscopy under homatropine is

$$
\begin{aligned}
& \text { Right eye }-875 \text { diop. spher. } \\
& \text { Left eye }=8.75 \text { diop. eylind. axis } 90^{\circ} \text {. }
\end{aligned}
$$

to have set forth upon a pitch dark night with neither moon nor stars, to have crossed country for half a mile climbing fences, finding gaps in hedges, and passing over a broad railway line, to have found and mutilated a pony which was loose in a large field, to have returned half a mile, and to have accomplished it all under 35 minutes, the limit of the the possible time at his disposal? Mr. Edalji did not wear spectacles."

A consensus of scientific opinion upon this point would greatly aid me in getting justice for this young professional man, condemned for an offence which in my opinion he could not possibly have committed.

I am, Sirs, yours faithfully,

ARthur Conan Dorle, M.D.

Undershaw, Hindhead, Surrey, Jan. 13th, 1907.

\section{AMYL NITRITE IN HÆMOPTYSIS.}

\section{To the Editors of THE LANCET.}

SIRS,-If I bave read him correctly, Dr. Albert Abrams in his two recent letters on the above subject maintains that amyl nitrite inbalation promotes hæmostasis of the lung largely through reflex action. The vapour of the drug stimulates the terminations of the vagus in the nasal mucosa. Thence reflexly the longitudinal muscular fibres of the bronchioles are made to contract and express the blood from the lung parenchyma. This seems overmuch to expect from the "weaker longitudinal fibres." But whether or no these be competent for the task, it is certain that amyl nitrite can render the lung more or less exsanguine without assistance from the nasal mucosa or its nerve supply. In the laboratory demonstrations by Pic and Petitjean, the lung was rendered so anæmic that when incised no single drop of blood escaped. Yet the amyl nitrite responsible for the result was injected into the femoral vein. Further, nitroglycerine given by the mouth has proved no mean substitute for amyl nitrite inhalation in some cases of bæmoptysis.

Referring to the inhibitory influence of amyl nitrite on uterine hæmorrhage, Dr. Abrams expresses the opinion that the drug "acts on the fibres of the uterus with secondary constriction of the blood-vessels." An action on the uterine musculature, so far as I know, has not been hitherto postulated of the drug. But even if true, how could such action explain the influence of amyl nitrite on the bæmorrhage which follows removal of parovarian cysts and on that which accompanies rupture of the sac in ectopic gestation?

In point of fact, the only physiological action of amyl nitrite which rests on any secure foundation is the sudden production of vaso-dilation-or, in other words, the sudden inhibition of vascular tone-in wide areas, if not generally; this being of necessity associated with a fall of blood pressure and a compensatory acceleration of the heart beat. All other actions ascribed to the drug would appear to depend on mere inference from preconceived theories. For example, from the relief sometimes afforded by it in the asthmatic paroxysm, amyl nitrite is inferred to have the power of relaxing the bronchial muscles. But the inference is unjustifiable because the view that asthma depends on bronchial constriction remains an unverified hypothesis. The only view of the mechanism of the asthmatic paroxysm which is consistent with the known physiological action of amyl nitrite, is the vaso-motor hypothesis: amyl nitrite relieves asthma by relaxing the peripheral vaso-constriction which is an essential factor in the bronchial vascular distension responsible for the obstruction to respiration. I am, Sirs, yours faitbfully,

Upper Norwood, Jan. 12th, 1907. FRANCIS HARE.

\section{GAS FIRES.}

\section{To the Editors of THE LANCET.}

SIRs, - We have read with interest Mr. Francis Jones's letter in THF LANCET of Dec. 15th last criticising the results of the recent inquiry held by the Coal Smoke Abatement Society on gas stoves and should be glad if you can find space for the following reply.

Length of the tests. - While admitting that, within limits, a long test is preferable to a short one, we consider that in practice a full working day is quite sufficient. In this conclusion we are supported by the accepted practice in the case of boiler trials. The purpose of the inquiry being to provide data upon whicl to base general conclusions as to gas stoves, an investigation into the behaviour of 25 different stoves in different rooms is surely far preferable to a test of only one stove in one room, however long continued, which was, we believe, the condition holding in Mr. Jones's experiments. We consider it quite impossible to arrive at sound general conclusions as to the value of gas-stoves from such a test, however instructive the results may be in other ways. A peculiarity in the room or stove may vitiate the entire results. 
Size of rooms. - We think this is important and must be taken into account in considering the results of the tests. It does not, however, in any way invalidate these results.

Carbon dioxide.-The amount of $\mathrm{CO}_{2}$ found in the rooms was small and very slightly increased above that in the air admitted. Why should the $\mathrm{CO}_{2}$ be increased if all the products of combustion are carried up the flue? Our observations showed that the ventilating effect of the stores was considerable. Mr. Jones does not state what was the ventilating effect of his stove.

Carbon monoxide.-There were three cases when this was detected in the room; one was a flueless stove, another was proved to have some defect in the joints, and the third case was probably also due to a leaky joint. These were exceptions, to be condemned individually, but not to base an adverse general conclusion upon.

Potassium permanganate test. - The dust somewhat vitiated this test. Its results were chiefly negative and not satisfactory as a basis of comparison; no conclusion was therefore drawn from it.

Smell.-Although many stoves caused a smell the fact that in 12 cases it was absent showed that smell is not an in. variable accompaniment of gas stoves and is avoidable by proper construction.

Humidity.-The actual humidity of the room air is no guide as to the effect of a stove or fire unless it is compared with that of the air before admission to the room. It was upon the alteration of humidity, therefore, that conclusions were based. In Mr. Jones's tests the temperature produced in the room with the gas fire was higher than that due to the coal fire, he does not state how much; but it is important to note that a difference of $4^{\circ} \mathrm{F}$. would more than account for the difference of humidity which he found between the gas and coal fires.

Musk plant test.--No conclusions as to the merits of the stoves were drawn from this test.

In conclusion, Mr. Jones's experiments were carried out in a very small room, of 935 cubic feet capacity, the air of which was obvious] $y$ vitiated from some source other than the stoves, since the $\mathrm{CO}_{2}$ often exceeded 10 parts in 10,000 in the morning, and averayed 3.039 in excess of that in the outer air, without any stove or fire in the room. The amount of air passed through the room per hour is not recorded by Mr. Jones, a serious omission; but it would seem from his results that the ventilation was deficient. Further, it is essential $(a)$ to determine where the air drawn into your room comes from, and $(b)$ to apply all the tests to the air before admission which you apply in the room. Otherwise the results are of jittle value. Mr. Jones did not do this.

It is to be noted that the conclusion drawn from the Coal Smoke Abatement Society's inquiry was not that all gas stoves are good, but rather that there is no inherent necessity why a gas stove or fire should not be as good as, or even better bygienicaliy than, a coal fire, provided it is intelligently constructed and properly fitted to a good flue.

\section{We are. Sirs, yours faithfully,}

H. A. DES Vaeux, M.D. Brux.

Honorary Treasurer, Coal Smoke Abatement Society. JOHN S. OWENS M.D., A.M.Inst. C.E.,

Jan. 15th, 1907. F.R.G.S.

\section{MEAT DIET AND THE TEETH. \\ To the Editors of THE LANCET.}

SIRs, - I shall be obliged if you will allow me briefly to supplement the remarks made by Dr. Chalmers Watson in ThE LANCET of Jan. $12 \mathrm{th}$ in reply to a letter by Dr. J. Sim Wallace which appeared in the issue for Jan. 5th. This most interesting investigation is still incomplete but is sufficiently advanced to justify one in publishing some general conclusions which may assist others working along similar lines.

In the first place, one is struck by the essential similarity in the pathological changes occurring in the teeth of rats and of man. In the three rats referred to by Dr. Chalmers Watson the teeth presented all the characteristics of "honey combed teeth" seen in children who have been improperly fed; and microscopically, too, allowing for natural differences in the histology of the teeth, the defects were similar to those found in huneycombed teeth in the human subject. One would almost feel inclined to apologise to those acquainted with comparative pathology for pressing this matter of the essential similarity of pathological processes in animals and in man, did one not orten meet with critics who deny it, although they unhesitatingly accept the principle of the similarity of physiological function.
The second noteworthy fact is that in spite of the striking alterations present in other organs of rats fed on a meat diet the teeth show no evidence of having suffered. This is what any dental physiologist would have expected and should afford food for reflection for those who are lamenting the "degeneracy of the teeth" of the present day. I have for several years had unique opportunities for studying this question in the class of patient who would be most likely to show signs of degeneracy and the results of these experimental investigations have strengthened my conviction that there is no evidence whatever of any "degeneration of the teeth" at the present time. We must, therefore in my opinion, look in other directions for the cause or causes of the increased prevalence of caries.

Edinburgh, Jan. 13th, 1907. I am, Sirs, yours faithfully, J. H. GiBBs.

\section{0 the Editors of THE LANOWT.}

SIRs, -Dr. Chalmers Watson contends that a dietary deficient in lime salts does not make the teeth susceptible to caries and that the facts ascertained from his investigation support the teachings of Dr. J. Sim Wallace on this subject. If this be so, it would be well to know further whether the artificial feeding of infants prejudicially affects the teeth, and whether it is true that artificially fed children are specially susceptible to dental caries as has been contended. I am, Sirs, yours faithfully,

Kingston-on-Thames, Jan. 13th, $1907 . \quad$ W. Geo. CREsweld

\section{TUBEROSE SCLEROSIS OF THE BRAIN.}

\section{To the Editors of THE LANCET.}

SiRs, - I have read with some interest the letter from the editor of Brain, published in THE LANCET of Jan. 12th, 1907. He is incorrect in supposing that Dr. A. W Campbell's work is "apparently unknown" to me. I am well acquainted with Dr. Campbell's paper on Cerebral Sclerosis, published in Brain, 1905, and the fact that the case of tuberose sclerosis occurring at the West Riding Asylum, Wakefield, differed in some important respects from the similar cases described by him was the chief reason that made me send my account of the case to THE LANCET for publication. - I am, Sirs, yours faithfully,

MARGARET B. DoBson, M.D. Lond.,

Jan. 14th, 1907 Pathologist to the West Riding Asylum, Wakefield.

\section{DUTY-FREE ALCOHOL FOR MEDICAL PURPOSES.}

\section{To the Editors of THW LANCHT.}

SIRS,-May I be permitted to correct one or two errors in your annotation under the above heading in your issue of Jan. 5th, 1907, p. 40. Your correspondent is in error in stating that the new grade of methylated spirit, "industrial methylated spirit," is " undenatured-namely, unmixed with naphtha." The Revenue Act, 1906 provided, it is true, for the omission of the three-ejghths of 1 per cent. by volume of mineral naphtha in industrial methylated spirit, but at the same time the wood naphtha was retained in smaller proportion, the new spirit containing the one-nineteenth part of word naphtha instead of the one-ninth part as contained in ordinary methylated spirit. The suggestion made by your correspondent that medical men should be allowed to employ industrial methylated spirit for external use has been in part anticipated by the Inland Revenue authorities, as the new Act provides for its use in the composition of soap, compound camphor, aconite, and belladonna liniments of he British Pharmacopoia. It remains to be seen whether the presence of 5 per cent. of wood naphtha in industrial methylated spirit will confer on the spirit the irritating properties that are associated with ordinary methylated spirit. If the new spirit should prove to be irritating the matter might be brought to the notice of the Inland Revenue authorities, who might allow a further reduction in the proportion of wood naphtba present or permit the employment of some other denaturing agent. An inquiry has recently been addressed to the Inland Revenue authorities ${ }^{1}$ as to whether it is permissible to use methylated spirit in preparations for ortward application if methylated spirit is prescribed by a medical practitioner. The secretary to the Board of Inland Revenue replied " that it is illegal to use methylated spirits 